\title{
Hierarchical Coupling of Molecular Dynamics and Micromechanics to Predict the Elastic Properties of Three-Phase and Four- Phase Silicon Carbide Composites
}

\author{
Olanrewaju Aluko ${ }^{1}$ \\ University of Michigan-Flint, Flint, MI, 48502, USA \\ Evan J. Pineda ${ }^{2}$, Trenton M. Ricks ${ }^{3}$, and Steven M. Arnold ${ }^{4}$ \\ NASA Glenn Research Center, Cleveland, OH, 44135, USA
}

\begin{abstract}
The results obtained from previously conducted molecular dynamics analysis of silicon carbide ( $\alpha-\mathrm{SiC}(6 \mathrm{H}, 4 \mathrm{H}, \& 2 \mathrm{H}-\mathrm{SiC}), \beta-\mathrm{SiC}(3 \mathrm{C} \mathrm{SiC}))$, silicon and boron nitride, were utilized as inputs in the MAC/GMC micromechanics software to model and evaluate the elastic properties of three-phase $\mathrm{SiC} / \mathrm{BN} / \mathrm{SiC}$ and four-phase $\mathrm{SiC} / \mathrm{BN} / \mathrm{Si} / \mathrm{SiC}$ composites. This method of analysis eliminates the need for back-calculation of the apparent properties of the base constituents from the measuredceramic matrix composites properties. The multiscale models are validated against the available data in literature.
\end{abstract}

\section{Introduction}

In the search for materials that can tolerate substantial stresses at hotter temperatures, applications such as jet and rocket engines, and space vehicles that must be able to withstand extremely harsh environment during the reentry, engineers have been devising tough, lightweight composites made of silicon carbide fibers, embedded in a ceramic material. Silicon carbide can withstand $2,000^{\circ} \mathrm{C}$ and this materials serves as a source of hope for tomorrow's engines that will need higher operating temperatures since hotter en gines are more fuel-efficient, produce more thrust and can carry larger loads (the key operating factors for spacecraft and advanced aircraft). In addition to heat engines and structural applications, silicon carbide ( $\mathrm{SiC}$ ) is a very promis ing semiconductor material for high -temperature, highfrequency and high-power optoelectronic devices. Ceramic matrix composites (CMCs) can be generally described as a material system comprised of fibers or particles embedded within a ceramic matrix. For example, silicon carbide/silicon carbide ( $\mathrm{SiC} / \mathrm{SiC}$ ) compos ites contain coated $\mathrm{SiC}$ fibers and a $\mathrm{SiC}$ matrix. Of particular interest for high temperature applications are $\mathrm{SiC} / \mathrm{SiCCMCs}$ that utilize a fiber coating composed of boron nitride (BN) [1-3].

$\mathrm{SiC}$ can exist in several crystalline phases including $\alpha-\mathrm{SiC}(6 \mathrm{H}, 4 \mathrm{H}$, and $2 \mathrm{H} \mathrm{SiC}), \beta-\mathrm{SiC}(3 \mathrm{C})$ and as an amorphous material (a-SiC) [4-7]. The BN coating contains amorphous $\mathrm{BN}(\mathrm{a}-\mathrm{BN})$ with a small volume fraction of layered hexagonal BN (h-BN) [8-9]. Finally, some unreacted silicon (Si) from proces sing exists in a crystalline (c-Si) or amorphous structure (a-Si). The molecular structure of the phases within the fiber, matrix, and coating influence the thermo-mechanical behavior of the composite and can be controlled through a combination of material processing methods including chemical vapor infiltration, melt infiltration, and polymer impregnation and pyrolys is [10, 11].

Previous work examined the influence of micromechanics idealization (GMC and HFGMC), for both ordered and disordered micros tructures, on the unidirectional and laminated composite effective properties, proportional limit stress (PLS) and fatigue life for a typical ceramic matrix composite with weak interface [12,13]. They also determined

\footnotetext{
${ }^{1}$ As sociate Profes sor, Department of Mechanical Engineering.

${ }^{2}$ Aeros pace Research Engineer, Multiscale and Multiphysics Modeling Branch, AIAA Senior Member.

${ }^{3}$ Aerospace Research Engineer, Multiscale and Multiphysics Modeling Branch, AIAA Member.

${ }^{4}$ Technical Lead, Multiscale and Multiphysics Modeling Branch, AIAA Member.
} 
the influence of ordered and dis ordered microstructures on the effective properties and fatigue life of graph ite/epoxy polymer matrix composites (PMCs) at low fiber volume fractions in the context of assessing the adv antages/limitations of the micromechanics idealization available within the general synergistic, multiscale-modeling framework for composites.

Because of flexibility in the arrangement of the different phases within a given constituent, in addition to the morphology of the constituents themselves within the composite (fibers and coating within the matrix), it may be possible to design $\mathrm{SiC} / \mathrm{SiC}$ composites to meet specific performance requirements. Validated numerical simulations can be utilized during the material design process, effectively widening the available design space and allowing for exploration of novel microstructures at a relatively low expense and rapid throughput compared to physical material production and testing. To achieve this, accurate data for the thermo-mechanical properties of the basic phases of the cons tituent materials in the composite must first be obtained through experimentation or simulation at nanoscale. Ref. [14] has done the preliminary work towards establishing a multis cale modeling framework to enable a link between molecular structure of the materials phases, the arrangement of the phases in the constituents, and the morphology of the constituents in the composite to the performance of the composite material. The focus of the current work is to develop micromechanics models at higher length scales for the an alysis of unidirectional $\mathrm{SiC} / \mathrm{SiC} \mathrm{CMCs}$. The established and validated molecular dynamics (MD) data for the mechanical properties of different possible material phases in a $\mathrm{SiC} / \mathrm{SiC}$ composite were utilized in this study for the micro-mechanical analysis of three-phase $\mathrm{SiC} / \mathrm{BN} / \mathrm{SiC}$ and four-phase $\mathrm{SiC} / \mathrm{BN} / \mathrm{Si} / \mathrm{SiC}$ composites [14]. These material constituent phases include $\alpha-\mathrm{SiC}(6 \mathrm{H}$, $4 \mathrm{H}$, and $2 \mathrm{H} \mathrm{SiC})$ as the matrix, $\beta-\mathrm{SiC}(3 \mathrm{C})$ as the fibers, amorphous $\mathrm{BN}(\mathrm{a}-\mathrm{BN})$ as a coating or interface, and the embedded crystalline $\mathrm{Si}$ in the matrix phase. The numerical predictions of the elastic properties of the CMCs are validated against experimental and numerical data available in the existing literature.

\section{Micromechanics Model for Three-phase $\mathrm{SiC} / \mathrm{BN} / \mathrm{SiC}$ and Four-phase $\mathrm{SiC} / \mathrm{BN} / \mathrm{Si} / \mathrm{SiC}$ Composites}

Micromechanics analy sis can be used to predict the effective response of heterogeneous materials at the continuum scale, and the properties of the constituents can be determined fromsimulations at the lower, atomis tic scales. In this study, continuum-level predictions were obtained using the generalized method of cells (GMC) micromechanics theory, where the in put data for the continuum s cale were output results from the MD data produced by Refs. [14-17]. The generalized method of cells for continuous (or discontinuous) fibrous composites utilizes a repeating unit cell (RUC) representing the periodic material microstructure which can consist of an arbitrary number of phases necessary to accurately model the composite material. For technical details on the mathematical homogenization and localization steps within GMC, the reader is referred to Ref. [17].

The micromechanics analy sis establis hes the overall (macroscopic) behavior of the multi-phase composite and is expressed as a constitutive relation between the average stress and strain, in conjunction with the effective elastic stiffness. The semi-analytical procedure is computationally efficient and provides solutions on the order of seconds. The GMC is implemented with the MAC/GMC s oftware package, developed by the NASA Glenn Research Center [18]. The software was used to execute the micromechanical analy sis, utilizing the corresponding properties of the micro-constituents of composites in the MAC/GMC analysis to simulate the three-phase $\mathrm{SiC} / \mathrm{BN} / \mathrm{SiC}$ and four-phase $\mathrm{SiC} / \mathrm{BN} / \mathrm{Si} / \mathrm{SiC}$ composites.

Previous work es tablis hed several MD models to predict the elas tic stiffness properties of several different phases of $\mathrm{SiC}, \mathrm{BN}$, and $\mathrm{Si}$ [14]. The advantage of using simulation to predict the properties of the base conditions of the composite are numerous. Conducting simulations at lower lengths scales avoids the need to back-calculate or calibrate the properties of the constituents against composite data. Such calibrations typically lead to data sets that are nonunique. In addition, the results from the subsequent micromechanics models are correlations, rather than true predictions, and do not offer any insight into the accuracy of the models for validation. Moreover, experiments at the lower length scales can be costly and time consuming, and also contain a degree of uncertainty and scatter [19-22]. The properties of the subcells in the different constituents ( $\mathrm{SiC}$ fiber, $\mathrm{BN}$ coating, free $\mathrm{Si}$, and $\mathrm{SiC}$ matrix) of the CMC RUCs were taken from the average values reported in Ref. 14 and are presented in Tables 1-3. The SiC fibers and matrix contain a combination of different $\mathrm{SiC}$ phases, but the exact phase-composition is difficult to determine. As an initial approximation, it is assumed that the fiber is composed of $\beta$-SiC and the matrix is $\alpha$-SiC. Different combinations of $\alpha$-SiC and amorphous boron nitride were used as matrixand interface, respectively with $\beta$-SiCfibers, in order to obtain bounds on the properties of the ceramic matrix composite. 
Table 1. Elastic response of $\mathrm{SiC}[14]$.

\begin{tabular}{|c|c|c|c|c|}
\hline Property & $\alpha(6 \mathrm{H})$ & $\alpha(4 \mathrm{H})$ & $\alpha(2 \mathrm{H})$ & $\beta(3 \mathrm{C})$ \\
\hline $\mathrm{E}_{\mathrm{x}}(\mathrm{GPa})$ & 543.1900 & 608.5120 & 437.9240 & 340.0000 \\
\hline $\mathrm{E}_{\mathrm{y}}(\mathrm{GPa})$ & 539.9330 & 529.7060 & 585.5070 & 343.2800 \\
\hline $\mathrm{E}_{\mathrm{z}}(\mathrm{GPa})$ & 617.9660 & 652.6440 & 600.6640 & 325.4000 \\
\hline $\mathrm{G}_{\mathrm{xy}}(\mathrm{GPa})$ & 252.4010 & 263.2470 & 147.6260 & 195.7470 \\
\hline $\mathrm{G}_{\mathrm{xz}}(\mathrm{GPa})$ & 225.7890 & 225.4510 & 165.2300 & 203.0700 \\
\hline $\mathrm{G}_{\mathrm{yz}}(\mathrm{GPa})$ & 218.7930 & 225.4360 & 225.5010 & 181.9890 \\
\hline$v_{\mathrm{xy}}$ & 0.2290 & 0.2117 & 0.2013 & 0.2558 \\
\hline$v_{\mathrm{xz}}$ & 0.0812 & 0.1048 & 0.0878 & 0.2442 \\
\hline$v_{\mathrm{yz}}$ & 0.0961 & 0.0798 & 0.0745 & 0.2546 \\
\hline
\end{tabular}

Table 2. Elastic response of a-BN [14].

\begin{tabular}{|l|l|}
\hline Property & $\begin{array}{l}\text { 5-layered } \\
\dot{\varepsilon}=10^{7} / \mathrm{s}\end{array}$ \\
\hline $\mathrm{E}_{\mathrm{x}}(\mathrm{GPa})$ & 46.3940 \\
\hline $\mathrm{E}_{\mathrm{y}}(\mathrm{GPa})$ & 46.7390 \\
\hline $\mathrm{E}_{\mathrm{z}}(\mathrm{GPa})$ & 56.4200 \\
\hline $\mathrm{G}_{\mathrm{xy}}(\mathrm{GPa})$ & 16.1680 \\
\hline$v_{\mathrm{xy}}$ & 0.2892 \\
\hline$v_{\mathrm{yx}}$ & 0.2974 \\
\hline
\end{tabular}

Table 3. Elastic response of $\mathrm{Si}$ [14].

\begin{tabular}{|l|l|}
\hline Property & Value \\
\hline $\mathrm{E}_{\mathrm{x}}(\mathrm{GPa})$ & 145.0410 \\
\hline $\mathrm{E}_{\mathrm{y}}(\mathrm{GPa})$ & 141.8900 \\
\hline $\mathrm{E}_{\mathrm{z}}(\mathrm{GPa})$ & 143.6830 \\
\hline $\mathrm{G}_{\mathrm{xy}}(\mathrm{GPa})$ & 54.9106 \\
\hline $\mathrm{G}_{\mathrm{xz}}(\mathrm{GPa})$ & 55.3215 \\
\hline $\mathrm{G}_{\mathrm{yz}}(\mathrm{GPa})$ & 54.0125 \\
\hline$v_{\mathrm{xy}}$ & 0.3207 \\
\hline$v_{\mathrm{xz}}$ & 0.3109 \\
\hline$v_{\mathrm{yz}}$ & 0.3135 \\
\hline
\end{tabular}

It should be noted that MAC/GMC has the ability to utilize many different micromechanics analysis models and RUC architectures for the CMC. Specific MAC/GMC commands are presented as COMMAND in this section. For this study, a user-defined architecture (ARCHID=99), was used to represent the RUCs for three-, and four-, phase CMC composites, displayed in Fig. 1 and 2, respectively. Figure 1 shows the RUC containing subcells of $\beta$-SiC fibers (blue), a-BN as the interphase (yellow), and $\alpha$-SiC as the matrix phase (green) to simulate three-phase $\mathrm{SiC} / \mathrm{SiC}$ composite. The four-phase RUC(Fig. 2) contains subcells of $\beta$-SiC fibers (blue), a-BN as the interphase (yellow), free Si that is embedded in matrix phase (sky blue) and $\alpha$-SiC as the matrix phase (green) and was originally developed as part of previous work [23]. For both models, the fiber volume fraction was 0.25 , and the ratio of interface thickness to fiber radius (RITFR) was 0.07 . In these simulations, linear elas tic constitutive model ( $C M O D=6)$ was used, the loading was strain control $(\mathrm{MOD}=1)$ with a strain magnitude of $2 \%$.

\section{Results and Discussions}

The three and four-phase CMC comprising $\alpha$-SiC structures, (6H SiC, $4 \mathrm{H} \mathrm{SiC}$, and $2 \mathrm{H} \mathrm{SiC}$ ), $\beta-\mathrm{SiC}(3 \mathrm{C}$ ), a-BN, and $\mathrm{Si}$ were modeled using the GMC micromechanics theory. As stated before, the elastic moduli, shear moduli, and Poisson's ratios for each model were obtained using the MAC/GMC software. The predicted mechanical properties for the three-phase $\mathrm{SiC} / \mathrm{BN} / \mathrm{SiC}$ and four-phase $\mathrm{SiC} / \mathrm{BN} / \mathrm{Si} / \mathrm{SiC}$ composites are documented in Tables 4 and 5, respectively. It can be seen from the data in these tables that different combination of the phases of crystalline $\alpha$-SiC $(6 \mathrm{H}, 4 \mathrm{H}$ and $2 \mathrm{H}$ ) and a-BN (obtained from different layers of $\mathrm{h}-\mathrm{BN}$ ), given a fixed volume fraction of $\beta$-SiC fibers (0.25), resulted in a range of CMC properties. The results show that the structural properties of the modeled CMCs 
depend substantially on the crystallinity of the matrix. The properties varied with different structures of $\alpha$-SiCbut did not exhibit any significant change with a-BN for either CMC composite.

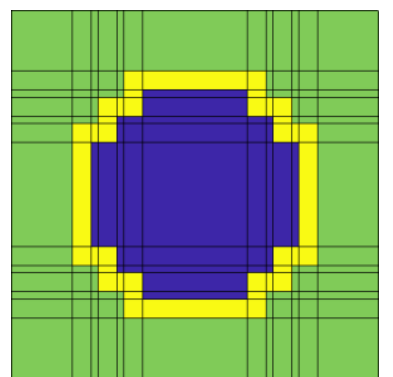

Fig. 1. The RUC architecture for a 3-phase $\mathrm{CMC}$, blue=SiC fiber, yellow=BN interface and green=SiC matrix.

Fig. 2. The RUC architecture for a 4-phase $\mathrm{CMC}$, blue=SiC fiber, yellow=BN interface, $\mathrm{sky}$ blue=free $\mathrm{Si}$, and green=SiC matrix [23].

Table 4. The properties for the three-phase composites when $\beta-\mathrm{SiC}$ is fiber, $\alpha-\mathrm{SiC}(6 \mathrm{H}, 4 \mathrm{H}$, or $2 \mathrm{H})$ is the matrix and $\mathrm{a}-\mathrm{BN}$ is the interface.

\begin{tabular}{|c|l|l|l|}
\hline Properties & $2 \mathrm{H}$ & $4 \mathrm{H}$ & $6 \mathrm{H}$ \\
\hline $\mathrm{E}_{11}(\mathrm{GPa})$ & 363.750 & 467.040 & 427.010 \\
\hline$v_{12}$ & 0.217 & 0.2259 & 0.2300 \\
\hline$v_{13}$ & 0.2174 & 0.2259 & 0.230 \\
\hline $\mathrm{E}_{22}(\mathrm{GPa})$ & 352.160 & 328.420 & 332.650 \\
\hline$v_{23}$ & 0.2050 & 0.218 & 0.218 \\
\hline $\mathrm{E}_{33}(\mathrm{GPa})$ & 352.160 & 328.420 & 332.650 \\
\hline $\mathrm{G}_{23}(\mathrm{GPa})$ & 108.860 & 103.930 & 104.650 \\
\hline $\mathrm{G}_{13}(\mathrm{GPa})$ & 104.750 & 156.630 & 151.880 \\
\hline $\mathrm{G}_{12}(\mathrm{GPa})$ & 104.750 & 156.630 & 151.880 \\
\hline
\end{tabular}

Table 5. The properties for the four-phase composites when $\beta-\mathrm{SiC}$ is fiber, $\alpha-\mathrm{SiC}(6 \mathrm{H}, 4 \mathrm{H}$, or $2 \mathrm{H})$ embedded with free $\mathrm{Si}$ is matrix and a-BN is the interface.

\begin{tabular}{|c|l|l|l|}
\hline Properties & $2 \mathrm{H}$ & $4 \mathrm{H}$ & $6 \mathrm{H}$ \\
\hline $\mathrm{E}_{11}(\mathrm{GPa})$ & 308.570 & 380.050 & 352.310 \\
\hline$v_{12}$ & 0.2412 & 0.247 & 0.2502 \\
\hline$v_{13}$ & 0.2407 & 0.247 & 0.2499 \\
\hline $\mathrm{E}_{22}(\mathrm{GPa})$ & 247.560 & 239.210 & 240.500 \\
\hline$v_{23}$ & 0.2795 & 0.289 & 0.2873 \\
\hline $\mathrm{E}_{33}(\mathrm{GPa})$ & 248.130 & 239.600 & 240.920 \\
\hline $\mathrm{G}_{23}(\mathrm{GPa})$ & 84.983 & 82.758 & 83.084 \\
\hline $\mathrm{G}_{13}(\mathrm{GPa})$ & 85.647 & 112.890 & 110.470 \\
\hline $\mathrm{G}_{12}(\mathrm{GPa})$ & 85.333 & 111.200 & 108.950 \\
\hline
\end{tabular}


Furthermore, comparing the data in Table 4 to Table 5, the CMC properties are influenced by the presence of free $\mathrm{Si}$. The Young's and shear moduli for the four-phase model are generally lower than that of three-phase model, while the Poisson's ratios for the four-phase are higher. This shows that the stiffness of the CMC matrix is compromised when there is free Si in the microstructure of the matrix. In Ref. [4], the fiber and matrix properties were backcalculated, while the coating properties were as sumed to match the experimental axial stiffness of $327 \mathrm{GPa}$ obtained from a heat-treated, cros s-ply CMClaminate. However, the results in this current work represent true predictions of the composite properties. It can be seen here that the 3-phase model over predicts the axial stiffness E11 (363.4 467.0 GPa), while the 4-phase model bounds the axial stiffness value (308.2 - 380.1 GPa). Similarly, the Young's modulus in the trans verse direction E22 and the computed shear modulus is as shown in Table 6 and compared with Ref. 4. The predictions of E22 from three-phase and four-phase models are slightly higher than Ref. [4], and the fourphase model exhibits the most accurate results. The shear modulus G12 from Ref. [4] falls within the range of the predicted values for the four-phase model but lower than that of three-phase model. Thus, it can be concluded that the addition of free-Si to the micromechanics model improved the accuracy of the effective stiffness predictions. Otherwise, the stiffness of the matrix must be artificially reduced to represent a homogenized SiC matrix containing the free $\mathrm{Si}$, and the model is no longer predictive.

Table 6. The range of predicted data as compared with Ref. 4.

\begin{tabular}{|l|l|l|l|}
\hline Properties & 3-phase & 4-phase & Ref. 4 \\
\hline $\mathrm{E}_{11}(\mathrm{GPa})$ & $363.75-467$ & $308.57-380.05$ & 327 \\
\hline $\mathrm{E}_{22}(\mathrm{GPa})$ & $328.42-352.16$ & $239.21-247.56$ & 216 \\
\hline $\mathrm{G}_{12}(\mathrm{GPa})$ & $104.75-156.63$ & $85.33-111.20$ & 90 \\
\hline
\end{tabular}

\section{Conclusion}

MAC/GMC was used to predict the mechanical properties of three-phase and four-phase CMC SiC composites. The microstructures of the constituents in the $\mathrm{SiC} / \mathrm{SiC}$ composites contain a variety of different phases comprising crystalline $\alpha-(6 \mathrm{H}, 4 \mathrm{H}$, and $2 \mathrm{H})$ and $\beta-\mathrm{SiC}(3 \mathrm{C})$, amorphous $\mathrm{BN}$, and free silicon ( $\mathrm{Si})$. Different microstructures of crystalline $\alpha-(6 \mathrm{H}, 4 \mathrm{H}$, and $2 \mathrm{H})$ and amorphous $\mathrm{BN}$ obtained from different layers of $h-\mathrm{BN}$ were utilized with fixed volume fractions of $\beta$-SiC fiber and free $\mathrm{Si}$. The properties of the constituents were obtained from MD simulations that were conducted as part of previous work. The current predictions of the constituent and composite were in good agreement with the available data in literature and serve as validation for the micromechanics and MD methods used. The predictions showed that the modeled properties of CMC composite s heavily depend on the microstructural constituents of the matrix, and indicate that explicit modeling of the free $\mathrm{Si}$ is likely needed for accurate predictions. As such, the model can be used to quickly assessthe amount of free $\mathrm{Si}$ in a CMCproduct, and/or determine the amount of free Si needed to meet particular performance requirements.

\section{Acknowledgments}

The summer faculty fellow, Olanrewaju Aluko thanks the entire staff in the office of education and training; it is remarkable to see this department acting as a gateway that ushers the young engineers and scientists to NASA. He also thanks the staff and research engineers in LMS department, and the staff in library of NASA Glenn Research Center, Cleveland, Ohio for making the summer fellows hip program very interesting and productive. The authors also thank Francisco Sola, Ram Bhatt, and Ibrahim Katampe for their support in this research work.

\section{References}

[1] Katoh, Y., Snead, L. L., Henager Jr., C. H. Nozawa, T., Hinoki, T., Ivekovíc, Novak, S., Gonzalez de Vicente, S. M. (2014). Current status and recent research achievements in SiC/SiC composites. Journal of Nuclear Materials, 455, 397-397.

[2] Bhatt, R. T., Chen, Y. L., Morscher, G. N. (2001). Microstructure and tensile properties of BN/SiC coated hi-nicalon, and sylramic SiC fiber preforms. NASA/TM-2001-210695.

[3] Meyer, P., Waas, A. M. (2016). FEM predictions of damage in continuous fiber ceramic matrix composites under transverse tension using the crack band method. Acta Materialia, 102, 292-303.

[4] Park, C.H., Cheong, B., Lee, K., Chang, K.J. (1994). Structural and electronic properties of cubic, 2H, 4H, and 6H SiC. Physical Review B, 49 (7), 4485-4493. 
[5] Liu, X., Li, L., Lu, F. (2013). Optical properties and mechanical properties of C, Si, Ge and 3C-SiC materials calculated from first principles theory using Heyd-Scuseria-Ernzerof functional. Materials Science in Semiconductor Processing, 16(6), 13691376.

[6] Bauer, A., Reischauer, P., Krausslich, J., Schell, N., Matz, W., Goetz, K. (2001. Structure refinement of silicon carbide polytypes $4 \mathrm{H}$ and $6 \mathrm{H}$ : unambiguous determination of the refinement parameters, Acta Crystallogr. Sec. A, 57, 60-67, doi:10.1107/S0108767300012915.

[7] Vashishta, P., Kalia, R. K., Nakano, A. (2007). Interaction potential for silicon carbide: A molecular dynamics study of elastic constants and vibrational density of states for crystalline and amorphous silicon carbide. Journal of Applied Physics, 101 (103515), 1-12.

[8] Singh, R. N., Brun, M. K. (1987). Effect of boron nitride coating on fiber-matrix interactions. Ceram. Eng. Sci. Proc., 8[7-8], 636-643.

[9] Morscher, G. M. Yun, H. M., DiCarlo, J. A., Thomas-Ogbuji, L. (2008). Effect of a boron nitride Interphase that debonds between the interphase and the matrix in $\mathrm{SiC} / \mathrm{SiC}$ composites. Journal of the American Ceramic Society, 87 (1), $104-112$

[10] Ortona, A., Donato, A., Filacchioni, G., De Angelis, U.,La Barbera, A., Nannetti, C., Riccardi, B., Yeat man, J. (2000). SiC$\mathrm{SiC}$ f CMC manufacturing by hybrid CVI-PIP techniques: process optimisation. Fusion Engineering and Design, 51, 159163

[11] Hillig, W. B. (1988). Melt infiltration approach to ceramic matrix composites. Journal of the American Ceramic Society, 71(2), c96-c99.

[12] Arnold, S. M., Mital, S., Murthy, P. L. N., Bednarcyk. B. A. (2016). Multiscale modeling of random microstructures in $\mathrm{SiC} / \mathrm{SiC}$ ceramic matrix composites within MAC/GMC framework. 31 st American Society of Composite Conference, October 19-22, 2016, Williamsburg, VA.

[13] Arnold, S. M., Murthy, P. L. N., Bednarcyk. B. A., Pineda, E. J. (2015). Microstructural influence on deformation and fatigue life of composites using generalized method of cells (GMC). 56th AIAA/ASME/ASCE/AHS/ASC Structures, Structural Dynamics, and Materials Conference, AIAA Science and Technology Forum, January 5-9, 2015, Kissimmee, FL.

[14] Aluko, O., Pineda, E. J., Ricks, T. M., Arnold, S. M. Molecular dynamics simulations of silicon carbide, boron nitride and silicon for ceramic composite applications. NASA/TM-2019-220305.

[15] Paley, M., Aboudi, J. (1992). Micromechanical analy sis of composites by the generalized cells model. Mech Mater., 14, 127-139.

[16] Bednarcyk, B. A., Aboudi, J., Arnold, S. M. (2014). The effect of general statistical fiber misalignment on predicted damage initiation in composites. Compos Part B-Eng., 66, 97-108.

[17] Aboudi, J., Arnold, S. M., Bednarcyk, B. A. (2013). Micromechanics of Composite Materials: A Generalized Multiscale Analysis Approach: Elsevier.

[18] Bednarcyk, B. A., Arnold, S. M. (2002). MAC/GMC User's Manual-Keywords Manual. NASA/TM-- 2002-212077/Vol2.

[19] Joel, J. P., Koo, B., Subramanian, N., Chattopadhyay A. (2017). Modelling the molecular structure of the carbon fiber/polymer interphase for multiscale analysis of composites. Composites Part B: Engineering, 111, 27-36.

[20] Sola, F., Bhatt, R. (2015). Mapping the local modulus of sylramic silicon carbide fibers by nanoindentation. Materials Letters, 159, 395-398.

[21] Bosak, A., Serrano, J., Krisch, M., Watanabe, K., Taniguchi, T., Kanda, H. (2006). Elasticity of hexagonal boron nitride inelastic X-ray scattering measurements. Physical Review B 73, 041402(R).

[22] Kamitani, K., Grimsditch, M., Nipko, J. C., Loong, C. -K., Okada, M., Kimura, I. (1997). The elastic constant of silicon carbide: A brillouin-scattering study of $4 \mathrm{H}$ and $6 \mathrm{H} \mathrm{SiC}$ single crystal. Journal of Applied Physics, 82 (6): 3152-3154.

[23] Arnold, S. M., Mital, S. K., Bednarcyk, B. A. Pineda, E. J. (2014). Micromechanics-based modeling of SiC/SiC composites. $38^{\text {th }}$ Annual Conference on Composites Materials, and Structures, January 27-30, 2017, Cocoa Beach, FL. 